This item was submitted to Loughborough's Research Repository by the author.

Items in Figshare are protected by copyright, with all rights reserved, unless otherwise indicated.

\title{
Hydrazine-free solution-deposited Culn(S,Se)2 solar cells by spray deposition of metal chalcogenides
}

PLEASE CITE THE PUBLISHED VERSION

http://dx.doi.org/10.1021/acsami.6b01541

\section{PUBLISHER}

American Chemical Society

VERSION

VoR (Version of Record)

\section{PUBLISHER STATEMENT}

This work is made available according to the conditions of the Creative Commons Attribution 4.0 International (CC BY 4.0) licence. Full details of this licence are available at: http://creativecommons.org/licenses/ by/4.0/

\section{LICENCE}

CC BY-NC-ND 4.0

\section{REPOSITORY RECORD}

Arnou, Panagiota, Maikel F.A.M. van Hest, Carl S. Cooper, Andrei V. Malkov, Michael Walls, and Jake W. Bowers. 2019. "Hydrazine-free Solution-deposited Cuin(s,se)2 Solar Cells by Spray Deposition of Metal Chalcogenides". figshare. https://hdl.handle.net/2134/21271. 


\title{
Hydrazine-Free Solution-Deposited Culn $(\mathrm{S}, \mathrm{Se})_{2}$ Solar Cells by Spray Deposition of Metal Chalcogenides
}

\author{
Panagiota Arnou, ${ }^{* \dagger}$ Maikel F.A.M. van Hest, ${ }^{\dagger}$ Carl S. Cooper, ${ }^{\dagger} \S$ Andrei V. Malkov, ${ }^{\S}$ John M. Walls, ${ }^{\dagger}$ \\ and Jake W. Bowers* ${ }^{\dagger}$
}

${ }^{\dagger}$ Centre for Renewable Energy Systems Technology (CREST), Wolfson School of Mechanical, Electrical and Manufacturing Engineering, and ${ }^{\S}$ Department of Chemistry, Loughborough University, Loughborough, Leicestershire LE11 3TU, United Kingdom ${ }^{\ddagger}$ National Renewable Energy Laboratory, 15013 Denver West Parkway, Golden, Colorado 80401-3305, United States

\section{Supporting Information}

ABSTRACT: Solution processing of semiconductors, such as $\mathrm{CuInSe}_{2}$ and its alloys (CIGS), can significantly reduce the manufacturing costs of thin film solar cells. Despite the recent success of solution deposition approaches for CIGS, toxic reagents such as hydrazine are usually involved, which introduce health and safety concerns. Here, we present a simple and safer methodology for the preparation of highquality $\mathrm{CuIn}(\mathrm{S}, \mathrm{Se})_{2}$ absorbers from metal sulfide solutions in a diamine/dithiol mixture. The solutions are sprayed in air, using a chromatography atomizer, followed by a postdeposition

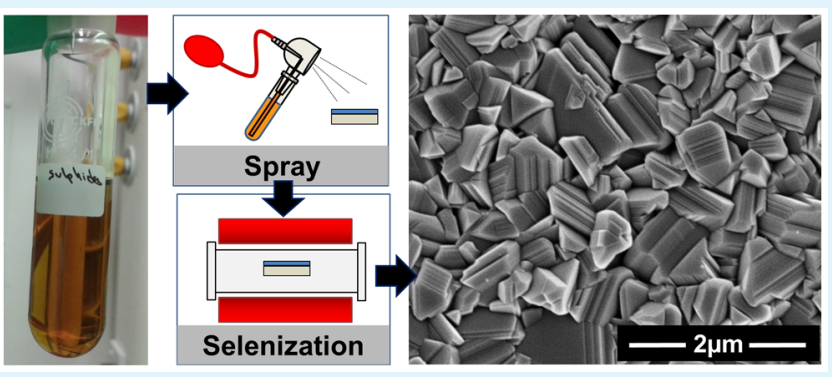
selenization step. Two different selenization methods are explored resulting in power conversion efficiencies of up to $8 \%$.

KEYWORDS: CIGS, thin film, solar cells, chalcopyrite, atmospheric process

$\mathrm{T}$ he use of vacuum-based deposition techniques for the preparation of chalcogenide absorber layers has resulted in highly efficient $\mathrm{Cu}$ (In,Ga) $\mathrm{Se}_{2}$ (CIGS) photovoltaic devices. ${ }^{1}$ Vacuum technologies, however, have a high capital cost, which is a major obstacle in the commercialization of CIGS. As a consequence, recent research on CIGS solar cells has been focused on developing solution-based approaches, where the deposition occurs under atmospheric conditions. These solution-based techniques are attractive, because the avoidance of high-vacuum processing equipment makes the process less expensive. Also, solution processes are more easily implemented in large area applications, as well as being better-suited to flexible substrates. ${ }^{2}$ To date, the most successful approach in terms of solar cell performance was developed by Todorov et al., who demonstrated a $15.2 \%$ efficient device. ${ }^{3}$ Their methodology involves the dissolution of metal chalcogenides $\left(\mathrm{Cu}_{2} \mathrm{~S}\right.$ and $\left.\mathrm{In}_{2} \mathrm{Se}_{3}\right)$ and $\mathrm{Ga}$ with excess chalcogen $(\mathrm{S}, \mathrm{Se})$ in hydrazine and the clean decomposition of the formed precursors. As opposed to other precursors which have been used for solution-processed CIGS deposition, ${ }^{4}$ metal chalcogenides are free from impurities, such as of halogens, carbon, or oxygen. These impurities can be easily incorporated into the thin film and as a consequence reduce device performance. However, metal chalcogenides are not easily dissolved in common solvents because of their strong covalent bonds, with hydrazine being the only solvent that can dissolve metal chalcogenides via the "dimensional reduction" process ${ }^{5}$ in the presence of excess chalcogen. Although hydrazine is an excellent solvent for this purpose, it is difficult to implement in large scale production because of its high toxicity and explosive nature. As a consequence, recent research on low-cost deposition techniques for CIGS solar cells has been focused on eliminating the use of hydrazine and substituting it with a safer solvent.

Recently, Webber et al. reported that nine $\mathrm{V}_{2} \mathrm{VI}_{3}$ chalcogenides (where $\mathrm{V}=\mathrm{As}, \mathrm{Sb}, \mathrm{Bi}$; and $\mathrm{VI}=\mathrm{S}, \mathrm{Se}, \mathrm{Te}$ ) can be dissolved at ambient conditions in a solvent mixture comprised of 1,2-ethanedithiol and 1,2-ethylenediamine. ${ }^{6}$ Our group has also reported that the same solvent mixture can be used for the dissolution of $\mathrm{Cu}_{2} \mathrm{~S}, \mathrm{Cu}_{2} \mathrm{Se}, \mathrm{In}_{2} \mathrm{~S}_{3}, \mathrm{In}_{2} \mathrm{Se}_{3}$ and that single phase $\mathrm{CuIn}(\mathrm{S}, \mathrm{Se})_{2}$ films can be obtained with good crystal growth after the selenization treatment of a spin-coated thin film. ${ }^{7}$ Duan et al. have shown that CdS and SnSe have a high solubility in the same solvent combination and $\mathrm{SnS}, \mathrm{CdSe}$, $\mathrm{ZnSe}$, and $\mathrm{MoS}_{2}$ can be dissolved at lower concentrations. ${ }^{8}$

Here our work is extended further by improving our precursor deposition and selenization methodology and by doing so, $\mathrm{CuIn}(\mathrm{S}, \mathrm{Se})_{2}$ (CISS) thin film absorber layers with high crystalline quality, suitable for solar cell applications, have been obtained.

The deposition of the precursor solution involved spraycoating instead of spin-coating. The spin-coated samples from our previous work ${ }^{7}$ were highly porous, which hindered the

Received: February 4, 2016

Accepted: May 2, 2016

Published: May 2, 2016 

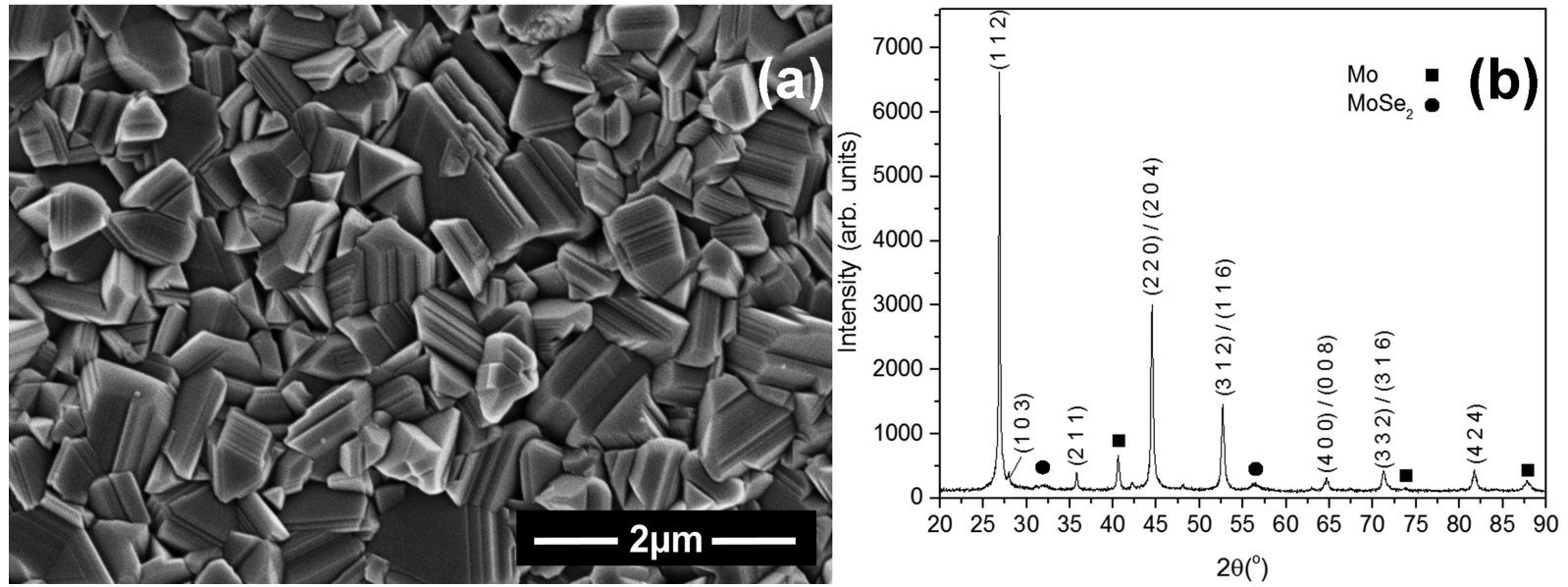

Figure 1. (a) SEM image of the top surface and (b) XRD pattern of a CISS film, selenized in the tube furnace.
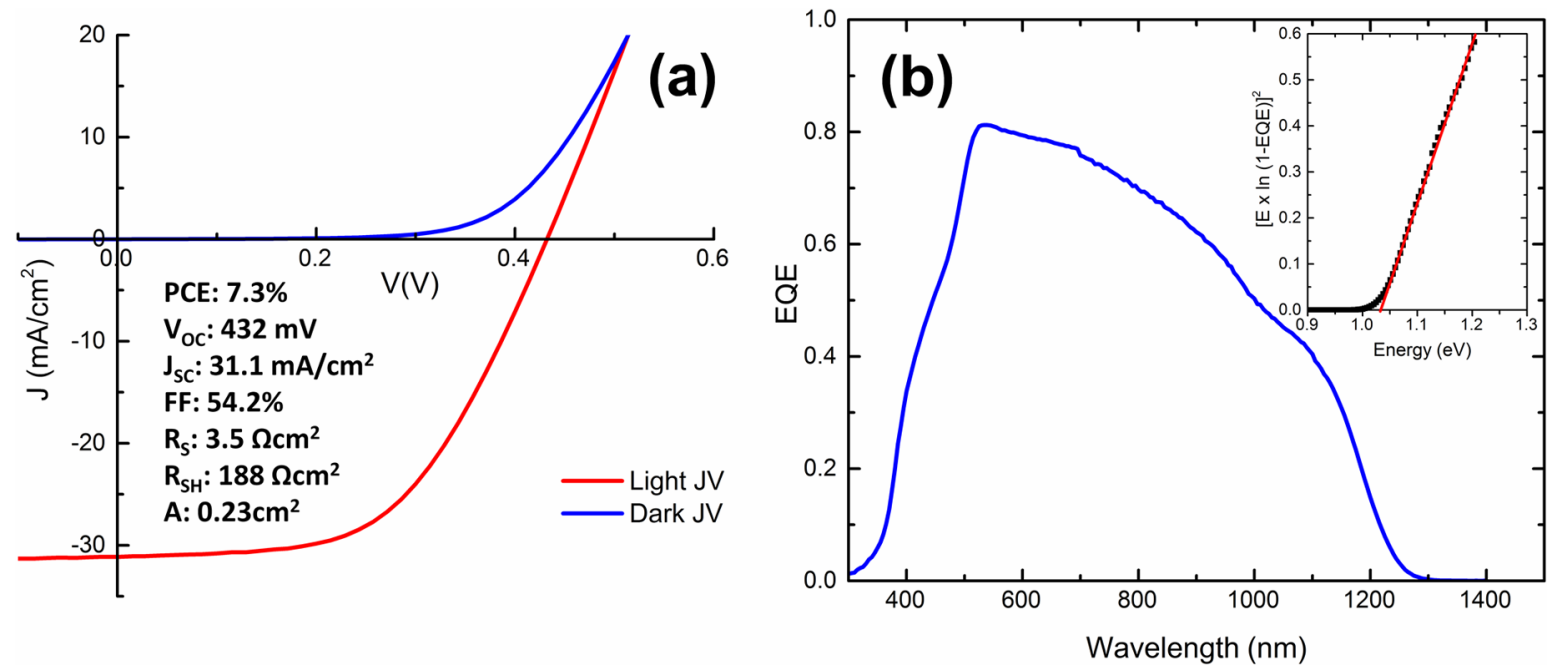

Figure 2. Electrical characteristics of the device processed in the tube furnace. (a) Light and dark JV curves (AM1.5G illumination, $100 \mathrm{~mW} \mathrm{~cm}^{-2}$ ). (b) External quantum efficiency (EQE) spectrum. Inset: estimation of the bandgap by extrapolation from the EQE data.

formation of highly crystallized and dense films. However, denser films are formed when spray deposition is used, because a thinner layer of the material is deposited at each deposition pass, when compared to the spin coating method. This minimizes the volume contraction and the formation of cracks that normally occur during thermal decomposition of the molecular complexes into an inorganic phase. ${ }^{9}$ The as-sprayed material is therefore much denser than the spin-coated material, which facilitates crystallization during the selenization step. Apart from the higher crystalline quality of the material, the use of spray deposition methods requires a smaller amount of starting material for the same film thickness, compared with spin-coating. This enables the thickness of the film to be built up easily and quickly. Spray deposition is a high-throughput and scalable technology and is very attractive from a manufacturing process viewpoint. The spray pyrolysis technique has been successfully implemented in literature for the preparation of CIGS from metal salts and thiourea. ${ }^{10}$ The drastic improvement in the film quality compared to our previous work ${ }^{7}$ was mostly obtained by substitution of spin coating with spray coating technique (denser as-deposited films). However, dilution of the precursor solution and the use of graphite box during selenization (see the Supporting
Information) showed additional improvement in the material quality.

The thin films are deposited in ambient atmospheric conditions within a fume hood using a glass chromatography atomizer. The solutions are prepared targeting a copper poor film stoichiometry (see the Supporting Information). The films are sprayed on a molybdenum coated glass substrate, placed on a preheated hot plate. An intermediate drying step is performed in- between the spraying of each layer. Finally, the postdeposition selenization treatment is performed in a tube furnace or a Rapid Thermal Processing (RTP) oven with selenium pellets. RTP was explored as an alternative selenization method in an effort to reduce the thermal treatment time and to improve the crystallization of the film and the device performance. By using RTP selenization, a power conversion efficiency (PCE) of $8.0 \%$ was obtained without an antireflection coating or grids, for a cell with an area of $0.24 \mathrm{~cm}^{2}$.

SEM and XRD were used to evaluate the surface morphology and the crystal structure of the absorber. Figure la shows an SEM image of an absorber surface, which was selenized in a tube furnace and deposited from a mixture of $\mathrm{Cu}_{2} \mathrm{~S}$ and $\mathrm{In}_{2} \mathrm{~S}_{3}$, targeting a copper poor ratio $(\mathrm{Cu} / \mathrm{In}=0.8)$ of the precursor. EDS analysis shows that the $\mathrm{Cu} / \mathrm{In}$ ratio remains approximately 

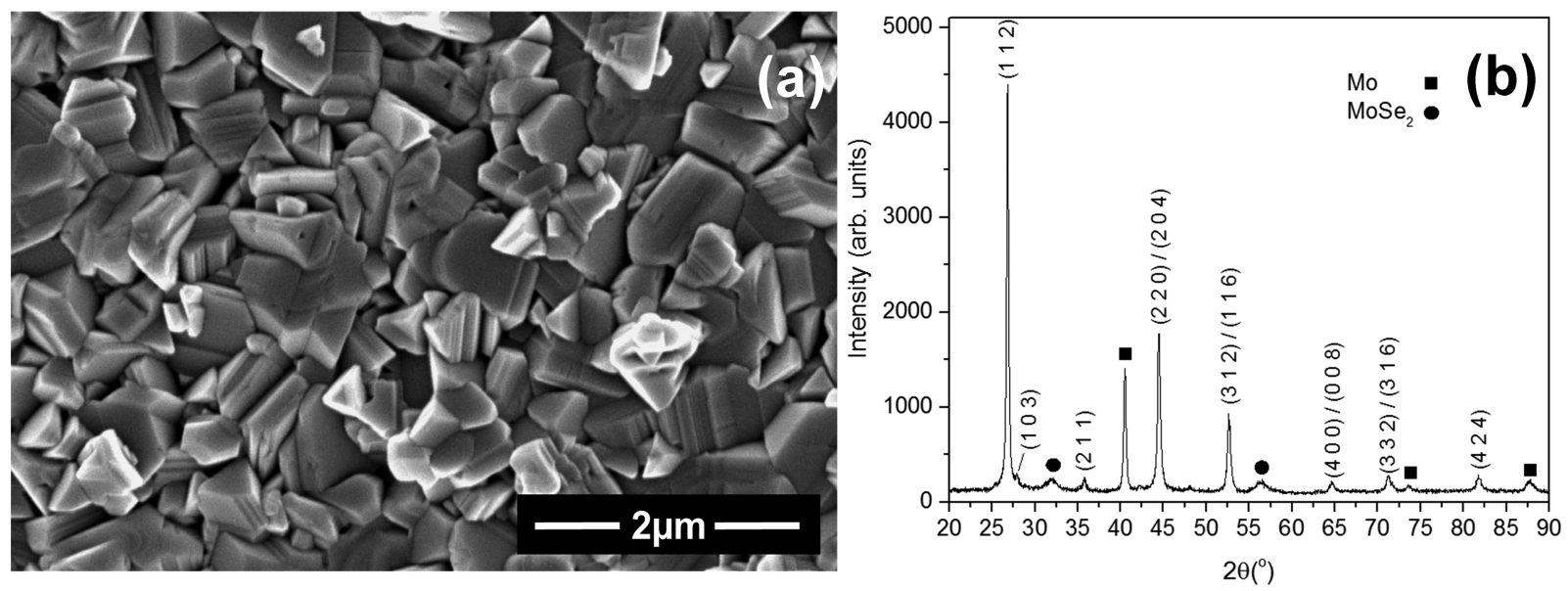

Figure 3. (a) SEM image of the top surface and (b) XRD pattern of a CISS film, selenized in the RTP oven.

constant for the as-deposited and selenized samples (Figures S3-S5). The top surface SEM image indicates that the films are homogeneous and crack-free, with the surface comprising of large grains of $1-1.5 \mu \mathrm{m}$ size. Figure $1 \mathrm{~b}$ shows the XRD spectrum of the same sample, which verifies the presence of a single-phase chalcopyrite material. Compared to the (112), $(220) /(204)$, and $(312) /(116)$ reflections of the $\mathrm{CuInSe}_{2}$ chalcopyrite phase that are expected at $2 \theta=26.58,44.23$, and $52.39^{\circ}$, respectively (JCPDS $40-1487$ ), the peaks are slightly shifted toward higher $2 \theta$ angles $(2 \theta=26.83,44.48$, and $52.63^{\circ}$, respectively). This is indicative of the decreasing $d$ spacing, as would be expected with increasing sulfur substitution in the crystal lattice. ${ }^{11}$ This shift indicates that only a small amount of sulfur is present in the film and that sulfur is mostly displaced by selenium during the selenization step. The broad peaks at $2 \theta \approx 32$ and $56^{\circ}$ (noted with circles) correspond to a $\mathrm{MoSe}_{2}$ layer, most likely located between the Mo and the absorber. Such an interfacial region creates an ohmic contact between the CIGS/CIS and Mo layer and it also improves the adhesion of the absorber to the Mo back contact. ${ }^{12}$ The XRD spectrum of the as-deposited sample (Figure S6) consists of two low-intensity peaks at $2 \theta \approx 28$ and $46.7^{\circ}$, which correspond either to the (112) and (220) peaks of $\mathrm{CuInS}_{2}$ (JCPDS $15-0681$ ), or to a $\mathrm{Cu}_{x} \mathrm{~S}$ phase. In combination with the EDS analysis (Figure S3), these results suggest that some $\mathrm{CuInS}_{2}$ is formed during spraying, with selenium displacing sulfur during selenization.

Figure 2a shows the current density-voltage $(J-V)$ characteristics of a device based on the tube furnace selenization approach, measured under dark and simulated AM1.5G illumination. These results are for the highest performing cell of the sample area $(2.5 \times 2.5 \mathrm{~cm})$. The configuration of the device was: $\mathrm{AZO} / \mathrm{iZnO} / \mathrm{CdS} / \mathrm{CISS} / \mathrm{Mo} /$ glass. A PCE of $7.3 \%$ was obtained, with an open circuit voltage $\left(V_{\text {oc }}\right)$ of $432 \mathrm{mV}$, a short circuit current density $\left(J_{\mathrm{sc}}\right)$ of $31.1 \mathrm{~mA}$ $\mathrm{cm}^{-2}$ and a fill factor (FF) of $54 \%$. The $V_{\mathrm{oc}}$ and $J_{\mathrm{sc}}$ of this device is comparable to that of a hydrazine-processed $\mathrm{CuIn}(\mathrm{S}, \mathrm{Se})_{2}$ solar cell with low sulfur content $\left(n=10.7 \%, V_{\mathrm{oc}}=440 \mathrm{mV}, J_{\mathrm{sc}}\right.$ $\left.=35.9 \mathrm{~mA} \mathrm{~cm}{ }^{-2}, \mathrm{FF}=67.5 \%\right){ }^{13}$ In comparison to the hydrazine-based device, our cell is limited by the low FF, which is mainly attributed to a high series resistance of $3.5 \Omega \mathrm{cm}^{2}$. This high series resistance can be related to excessive formation of $\mathrm{MoSe}_{2}{ }^{12}$ and the incomplete crystallization of the absorber throughout its thickness. It is expected that further improvement of the selenization step, the transparent conductive oxide
(TCO) deposition, as well as the evaporation of current collecting grids will increase the FF of the device significantly. In parallel with these improvements, the formation of $\mathrm{MoSe}_{2}$ will be carefully optimized.

Figure $2 \mathrm{~b}$ shows the external quantum efficiency (EQE) measurement of the same device. The observed decrease in EQE at wavelengths below $550 \mathrm{~nm}$ corresponds to the absorption of the CdS buffer layer. The EQE data shows good collection efficiency from 550 to $700 \mathrm{~nm}$, but the collection is reduced gradually at longer wavelengths. The drop in EQE at wavelengths $>700 \mathrm{~nm}$ indicates that there is high recombination toward the back of the absorber. This suggests that the device is not fully recrystallized throughout the thickness and that the selenization step should be improved further. The band gap $\left(E_{\mathrm{g}}\right)$ was estimated from the EQE curve, by plotting $[\mathrm{E} \cdot \ln (1-\mathrm{EQE})]^{2}$ versus $E^{14}$ (shown in the inset of Figure $2 \mathrm{~b}$ ), where $E_{\mathrm{g}}$ was extracted from the band edge by extrapolating to the horizontal axis intercept. The estimated bandgap of $1.06 \mathrm{eV}$ corresponds to $\mathrm{CuIn}(\mathrm{S}, \mathrm{Se})_{2}$ with low sulfur content. On the basis of previous work that associates the $\mathrm{S} / \mathrm{Se}$ ratio with the band gap (assuming a linear relationship between the bandgap values of $\mathrm{CuInSe}_{2}$ and $\left.\mathrm{CuInS}_{2}\right),{ }^{11,15}$ the estimated band gap from the QE data corresponds to a sulfur content of 4 at $\%$. This result suggests that sulfur is mostly displaced by selenium during selenization, in agreement with the XRD data and EDS analysis.

The selenization process needs to be optimized for the complete crystallization of the absorber to further improve performance. A longer selenization time could potentially improve the crystallization, but it may also increase further the series resistance by excessive $\mathrm{MoSe}_{2}$ formation. A different procedure was therefore used for a CISS sample deposited with the same conditions. An alternative selenization approach using an RTP oven was explored, which enables a significantly higher heating ramp rate compared to the tube furnace. Apart from being attractive as a low cost technique since it has a shorter processing time and lower thermal budget, use of RTP improves the material quality of chalcopyrites. Specifically, it was reported that the use of RTP resulted in improved crystal growth as detrimental phases can be avoided by passing intermediate formation temperatures rapidly. ${ }^{16}$ Also, a different TCO layer combination was used compared to the previous device. The configuration of the RTP processed device was: $\mathrm{IZO} / \mathrm{ZTO} / \mathrm{CdS} / \mathrm{CISS} / \mathrm{Mo} /$ glass (see the Supporting Information). It should be noted that these two devices were completed 

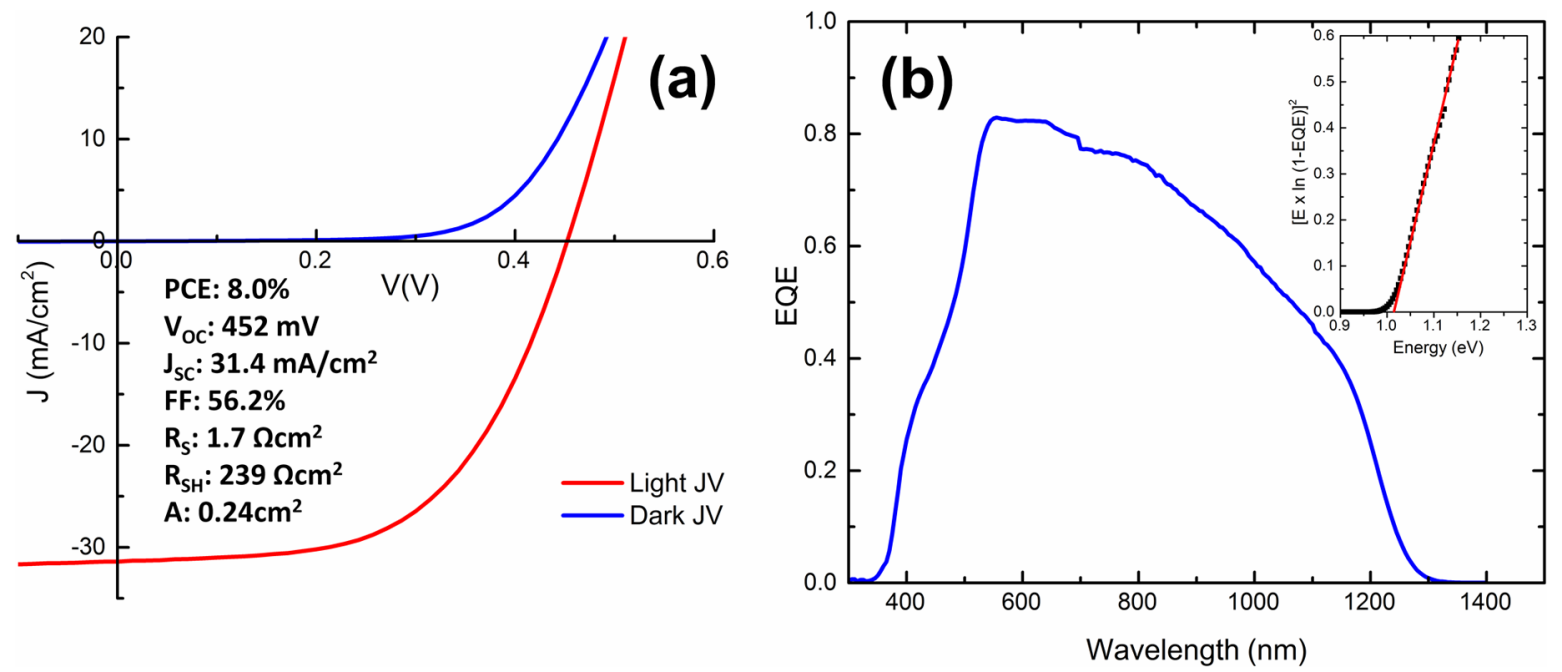

Figure 4. Electrical characteristics of the device processed using the RTP approach. (a) Light and dark J-V curves (AM1.5G illumination, $100 \mathrm{~mW}$ $\mathrm{cm}^{-2}$ ). (b) External quantum efficiency (EQE) spectrum. Inset: estimation of the bandgap by extrapolation from the EQE data.

in different laboratories; therefore different configurations were employed according to the respective lab standard process (between Loughborough and NREL). Although a direct comparison between devices is difficult to make, because of the different TCOs and buffer layers used, we are highlighting the merits of each selenization process in terms of crystal growth and $\mathrm{MoSe}_{2}$ formation.

Figure 3a shows the SEM image of the absorber top surface of a sister sample, selenized in the RTP oven. Information on the instrumentation, temperature profiles, and composition of the sample is given in the Supporting Information. The SEM image indicates that the films are homogeneous and crack-free, with grains of up to $1 \mu \mathrm{m}$ size. Figure $3 \mathrm{~b}$ shows the XRD spectrum of the sample, which verifies the presence of a singlephase chalcopyrite material. The $\mathrm{MoSe}_{2}$ peaks are evident, as in the case of the sample selenized in the tube furnace. The intensities of the $\mathrm{MoSe}_{2}$ (100) and Mo (110) diffractions can be related to the thickness of the $\mathrm{MoSe}_{2}$ layer. ${ }^{12}$ Here, the intensity ratio of the $\mathrm{Mo} / \mathrm{MoSe}_{2}$ peaks (at $2 \theta \approx 40$ and $32^{\circ}$ ) is higher for the RTP-processed sample (6.1 compared to 3.5). This suggests that the $\mathrm{MoSe}_{2}$ layer is thinner for the RTPprocessed sample. Raman was also performed in combination with XRD to verify the absence of secondary phases (Figure S7). A peak at $\sim 175 \mathrm{~cm}^{-1}$ is identified as the A1 peak of chalcopyrite CuInSe $e_{2}$ and a double peak is identified as the B2 or E mode. ${ }^{17}$

Figure 4a shows the dark and light $J-V$ curves for a device, with the absorber selenized in the RTP oven. The highest performing cell of the sample area $(2.5 \times 2.5 \mathrm{~cm})$ has a PCE, $V_{\text {oc }} J_{\text {sc }}$ and FF of $8.0 \%, 452 \mathrm{mV}, 31.4 \mathrm{~mA} \mathrm{~cm}{ }^{-2}$, and $56 \%$, respectively. In comparison to the $7.3 \%$ cell, the RTP-selenized device has a slightly improved $V_{\text {oc }}$ and a lower series resistance, which results in a better FF. The lower series resistance could be attributed to the shorter annealing time, which results in a thinner $\mathrm{MoSe}_{2}$ layer formation at the interface. This is in agreement with the XRD spectra and the cross sectional SEM images of the two devices, which are shown in Figure S8. The cross-sectional images show a similar crystallization of the absorber for the two cells with $\sim 600$ and $500 \mathrm{~nm}$ thick crystalline layer for the tube furnace and RTP-processed cell, respectively. This might suggest that the small difference in the series resistance is mainly attributed to the different $\mathrm{MoSe}_{2}$ thickness, which is indicated in the images.

Figure $4 \mathrm{~b}$ shows the EQE measurement of the RTP processed device. In comparison with the previous device, there is a decrease in collection below $550 \mathrm{~nm}$, good collection efficiency from about 550 to $700 \mathrm{~nm}$ and a reduced collection at longer wavelengths. This indicates that the absorber is not fully recrystallized throughout its thickness, which is also shown in the cross sectional SEM images of Figure S8. In comparison to the EQE of Figure $2 b$, this cell has a slightly better collection at longer wavelengths. This could be attributed to a slight improvement in the absorber quality or the use of a different TCO layer combination.

The estimation of the band gap $\left(E_{\mathrm{g}}\right)$ is shown in the inset of Figure $4 \mathrm{~b}$ and equals to $1.03 \mathrm{eV}$, which corresponds to pure $\mathrm{CuInSe}_{2} \cdot{ }^{11,18}$ This verifies that sulfur is mostly displaced by selenium during the selenization process, within the accuracy of this calculation.

Overall, the EQE data shows that both devices have good collection but room for improvement remains. Specifically, further optimization of the selenization process should result in the complete crystallization of the absorber, which will improve the EQE at longer wavelengths and consequently the $J_{\mathrm{sc}}$ of the device. Apart from the selenization step, there is room for improvement in terms of the deposition and drying steps, in order to eliminate small voids (up to $200 \mathrm{~nm}$ ) in the asdeposited film.

In summary, we have developed an atmospheric solutionbased process for the deposition of $\mathrm{CuIn}(\mathrm{S}, \mathrm{Se})_{2}$ absorbers, using a safer solvent combination than hydrazine, combined with metal chalcogenide precursors. Using this approach, we have fabricated a $8.0 \% \mathrm{CuIn}(\mathrm{S}, \mathrm{Se})_{2}$ solar cell, with the performance of this device limited by high series resistance and incomplete recrystallization throughout the absorber. On the basis of these promising results, there is scope for further improvement of this new approach. Specifically, the increase in the band gap, by incorporating excess gallium or sulfur in the process, would result in an increase of the $V_{\text {oc }}$ and an improvement in conversion efficiency. Also, no sodium or antimony dopants have been used intentionally in this process. These dopants have been shown to improve the electronic 
properties $^{19}$ and enhance the grain growth of $\mathrm{CIGS}^{20}$ respectively.

It is anticipated that further optimization of the device processing will result in higher device performance. The proposed approach using safer solvents than hydrazine has the potential for large scale manufacturing thin film CIGS devices. The deposition procedure is performed in air and avoids complicated precursor synthesis. It is a simple and easily controlled process. The use of a safer solvent mixture and the simplicity of this method have the potential to lead to an industrially scalable solution deposition methodology for CIGS.

\section{ASSOCIATED CONTENT}

\section{S Supporting Information}

The Supporting Information is available free of charge on the ACS Publications website at DOI: 10.1021/acsami.6b01541.

Experimental and measurement details; digital photographs of the enclosures used; temperature profiles; EDS compositional analysis of as-deposited and selenized samples; top surface SEM image and XRD spectrum of as-deposited sample; Raman spectra the selenized samples; cross-sectional SEM images of the two devices (PDF)

\section{AUTHOR INFORMATION}

\section{Corresponding Authors}

*E-mail: P.Arnou@lboro.ac.uk.

*E-mail: J.W.Bowers@lboro.ac.uk.

Notes

The authors declare no competing financial interest.

\section{ACKNOWLEDGMENTS}

The authors thank Dr. Stephen Whitelegg, Nanoco Technologies plc (UK) for the EQE measurements, and Dr. Ali. Abbas (Loughborough University), for the SEM images. Authors P.A, C.S.C, J.M.W., and J.W.B. are grateful for funding from EPSRC Supergen SuperSolar Hub (EP/J017361/1); EPSRC PVTEAM (EP/L017792/1) and EPRSRC grant EP/ N508457/1 to support this project. P.A. also thanks the SuperSolar Hub for funding a 3 month secondment at the National Renewable Energy Laboratory in Colorado, USA.

\section{REFERENCES}

(1) Jackson, P.; Hariskos, D.; Wuerz, R.; Kiowski, O.; Bauer, A.; Friedlmeier, T. M.; Powalla, M. Properties of $\mathrm{Cu}(\mathrm{In}, \mathrm{Ga}) \mathrm{Se} 2$ Solar Cells with New Record Efficiencies up to $21.7 \%$. Phys. Status Solidi RRL 2015, 9, 28-31.

(2) Todorov, T.; Mitzi, D. B. Direct Liquid Coating of Chalcopyrite Light-Absorbing Layers for Photovoltaic Devices. Eur. J. Inorg. Chem. 2010, 2010, 17-28.

(3) Todorov, T. K.; Gunawan, O.; Gokmen, T.; Mitzi, D. B. Solutionprocessed $\mathrm{Cu}(\mathrm{In}, \mathrm{Ga})(\mathrm{S}, \mathrm{Se}) 2$ Absorber Yielding a $15.2 \%$ Efficient Solar Cell. Prog. Photovoltaics 2013, 21, 82-87.

(4) Ahn, S.; Kim, C.; Yun, J. H.; Gwak, J.; Jeong, S.; Ryu, B.; Yoon, K. CuInSe2 (CIS) Thin Film Solar Cells by Direct Coating and Selenization of Solution Precursors. J. Phys. Chem. C 2010, 114, $8108-8113$.

(5) Mitzi, D. B. Solution Processing of Chalcogenide Semiconductors via Dimensional Reduction. Adv. Mater. 2009, 21, 3141-3158.

(6) Webber, D. H.; Brutchey, R. L. Alkahest for V2VI3 Chalcogenides: Dissolution of Nine Bulk Semiconductors in a Diamine-dithiol Solvent Mixture. J. Am. Chem. Soc. 2013, 135, 15722-15725.
(7) Arnou, P.; Cooper, C. S.; Malkov, A. V.; Bowers, J. W.; Walls, J. M. Solution-processed CuIn(S,Se)2 Absorber Layers for Application in Thin Film Solar Cells. Thin Solid Films 2015, 582, 31-34.

(8) Lin, Z.; He, Q.; Yin, A.; Xu, Y.; Wang, C.; Ding, M.; Cheng, H.; Papandrea, B.; Huang, Y.; Duan, X. Cosolvent Approach for SolutionProcessable Electronic Thin Films. ACS Nano 2015, 9, 4398-4405.

(9) Jiang, C.; Lee, J.; Talapin, D. V. Soluble Precursors for CuInSe2, CuIn1-xGaxSe2, and $\mathrm{Cu} 2 \mathrm{ZnSn}(\mathrm{S}, \mathrm{Se}) 4$ Based on Colloidal Nanocrystals and Molecular Metal Chalcogenide Surface Ligands. J. Am. Chem. Soc. 2012, 134, 5010-5013.

(10) Hossain, M. A.; Tianliang, Z.; Keat, L. K.; Xianglin, L.; Prabhakar, R. R.; Batabyal, S. K.; Mhaisalkar, S. G.; Wong, L. H. Synthesis of $\mathrm{Cu}(\mathrm{In}, \mathrm{Ga})(\mathrm{S}, \mathrm{Se}) 2$ Thin Films Using an Aqueous Spraypyrolysis Approach, and Their Solar Cell Efficiency of 10.5\%. J. Mater. Chem. A 2015, 3, 4147-4154.

(11) Hou, W. W.; Bob, B.; Li, S.; Yang, Y. Low-temperature Processing of a Solution-deposited CuInSSe Thin-film Solar Cell. Thin Solid Films 2009, 517, 6853-6856.

(12) Zhu, X.; Zhou, Z.; Wang, Y.; Zhang, L.; Li, A.; Huang, F. Determining Factor of $\mathrm{MoSe} 2$ Formation in $\mathrm{Cu}(\mathrm{In}, \mathrm{Ga}) \mathrm{Se} 2$ Solar Cells. Sol. Energy Mater. Sol. Cells 2012, 101, 57-61.

(13) Liu, W.; Mitzi, D. B.; Yuan, M.; Kellock, A. J.; Chey, S. J.; Gunawan, O. $12 \%$ Efficiency $\mathrm{CuIn}(\mathrm{Se}, \mathrm{S}) 2$ Photovoltaic Device Prepared Using a Hydrazine Solution Process $†$. Chem. Mater. 2010, 22, 1010-1014.

(14) Woo, K.; Kim, Y.; Moon, J. A Non-toxic, Solution-processed, Earth Abundant Absorbing Layer for Thin-film Solar Cells. Energy Environ. Sci. 2012, 5, 5340-5345.

(15) Bob, B.; Lei, B.; Chung, C.-H.; Yang, W.; Hsu, W.-C.; Duan, H.S.; Hou, W. W.-J.; Li, S.-H.; Yang, Y. The Development of HydrazineProcessed $\mathrm{Cu}(\mathrm{In}, \mathrm{Ga})(\mathrm{Se}, \mathrm{S}) 2$ Solar Cells. Adv. Energy Mater. 2012, 2, 504-522.

(16) Siemer, K.; Klaer, J.; Luck, I.; Bruns, J.; Klenk, R.; Bräunig, D. Efficient CuInS2 Solar Cells from a Rapid Thermal Process (RTP). Sol. Energy Mater. Sol. Cells 2001, 67, 159-166.

(17) Neumann, H. Lattice Vibrational, Thermal and Mechanical Properties of CuInSe2. Sol. Cells 1986, 16, 399-418.

(18) Stanbery, B. J. Copper Indium Selenides and Related Materials for Photovoltaic Devices. Crit. Rev. Solid State Mater. Sci. 2002, 27, $73-117$.

(19) Erslev, P. T.; Shafarman, W. N.; Cohen, J. D. Metastable Properties of $\mathrm{Cu}(\operatorname{In}[1-\mathrm{x}] \mathrm{Ga}[\mathrm{x}]) \mathrm{Se} 2$ with and Without Sodium. Appl. Phys. Lett. 2011, 98, 062105.

(20) Yuan, M.; Mitzi, D. B.; Liu, W.; Kellock, A. J.; Chey, S. J.; Deline, V. R. Optimization of CIGS-Based PV Device Through Antimony Doping. Chem. Mater. 2010, 22, 285-287. 